\title{
Superhydrophobic Coatings Based on Siloxane Resin and Calcium Hydroxide Nanoparticles for Marble Protection
}

\author{
Aikaterini Chatzigrigoriou ${ }^{1}$, Ioannis Karapanagiotis ${ }^{2, *(D)}$ and Ioannis Poulios ${ }^{1}$ \\ 1 Department of Chemistry, Aristotle University of Thessaloniki, 54124 Thessaloniki, Greece; \\ katerinaxatzigrigoriou@yahoo.gr (A.C.); poulios@chem.auth.gr (I.P.) \\ 2 Department of Management and Conservation of Ecclesiastical Cultural Heritage Objects, University \\ Ecclesiastical Academy of Thessaloniki, 54250 Thessaloniki, Greece \\ * Correspondence: y.karapanagiotis@aeath.gr
}

Received: 12 March 2020; Accepted: 27 March 2020; Published: 1 April 2020

\begin{abstract}
Calcium hydroxide $\left(\mathrm{Ca}\left(\mathrm{OH}_{2}\right)\right)$ nanoparticles are produced following an easy, ion exchange process. The produced nanoparticles are characterized using transmission electron microscopy (TEM) and Fourier- transform infrared spectroscopy (FTIR) and are then dispersed in an aqueous emulsion of silanes/siloxanes. The dispersions are sprayed on marble and the surface structures of the deposited coatings are revealed using scanning electron microscopy (SEM). By adjusting the nanoparticle concentration, the coated marble obtains superhydrophobic and water repellent properties, as evidenced by the high static contact angles of water drops $\left(>150^{\circ}\right)$ and the low sliding angles $\left(<10^{\circ}\right)$. Because $\mathrm{Ca}(\mathrm{OH})_{2}$ is chemically compatible with limestone-like rocks, which are the most common stones found in buildings and objects of the cultural heritage, the produced composite coatings have the potential to be used for conservation purposes. For comparison, the wetting properties of another superhydrophobic and water repellent coating composed of the same siloxane material and silica $\left(\mathrm{SiO}_{2}\right)$ nanoparticles, which were commonly used in several previously published reports, were investigated. The suggested siloxane $+\mathrm{Ca}(\mathrm{OH})_{2}$ composite coating offers good protection against water penetration by capillarity and has a small effect on the aesthetic appearance of marble, according to colorimetric measurements.
\end{abstract}

Keywords: superhydrophobic; water repellency; calcium hydroxide; siloxane; marble; cultural heritage; conservation

\section{Introduction}

Recent advances in coating materials may offer novel routes for effective and sustainable protection and preservation of natural stone used in cultural heritage [1]. For example, superhydrophobic and water repellent coating materials can offer protection against the deteriorative effects of rainwater, as they can reduce the penetration of atmospheric liquid water into the pore network of natural stone.

The static contact angle (CA) of a water drop on a superhydrophobic surface is CA $>150^{\circ}$, whereas the sliding angle (SA) of a water drop on a water repellent surface is $\mathrm{SA}<10^{\circ}$. Superhydrophobicity is usually (e.g., lotus leaf [2]), but not always (e.g., rose petal [3]), accompanied by water repellency. Therefore, both CA and SA are important to actually characterize the wetting properties of a material.

Research results of the last fifteen years have shown that an easy and effective strategy to produce superhydrophobic and water repellent coatings is the integration (addition) of nanoparticles into a low surface energy polymer matrix $[4,5]$. Nanoparticles enhance surface roughness, which is the key parameter to achieve extreme wetting properties. This method was suggested to produce polymer+nanoparticle composite coatings for the protection of natural stone in 2007 [6] and was 
established through relevant detailed studies in 2009 [7,8]. In these early works, silica $\left(\mathrm{SiO}_{2}\right)$ nanoparticles were used as additives to roughen the surface of siloxane, acrylic, and perfluorinated polymer coatings [6-8]. Since then, $\mathrm{SiO}_{2}$ nanoparticles have become the standard additives for the production of superhydrophobic polymer+nanoparticle composite coatings for natural stone protection [9-17]. Other nanoparticles, selected for the same purpose, are aluminum oxide $\left(\mathrm{Al}_{2} \mathrm{O}_{3}\right)$ [8] and tin oxide $\left(\mathrm{SnO}_{2}\right)$ [8], as well as photo-catalytic and biocidal nanomaterials, such as titanium oxide $\left(\mathrm{TiO}_{2}\right)[8,13,18-21]$, zinc oxide $(\mathrm{ZnO})[12,19]$, and silver $(\mathrm{Ag})$ [22].

The goal of the present short study is to produce a superhydrophobic and water repellent siloxane-based composite coating by adding calcium hydroxide $\left(\mathrm{Ca}(\mathrm{OH})_{2}\right)$ nanoparticles. Unlike the nanoparticles described above and those used in the past, $\mathrm{Ca}(\mathrm{OH})_{2}$ is chemically compatible with limestone and limestone-like rocks (marble, travertine), which are undoubtfully the most common stones that have been used in the past [1]. Nanoparticles of $\mathrm{Ca}(\mathrm{OH})_{2}$ are produced, characterized, mixed with a siloxane-based precursor in various concentrations, and sprayed onto marble specimens to evaluate the wettabilities of the produced composite coatings. For comparative purposes, other composite coatings were prepared using the standard $\mathrm{SiO}_{2}$ nanoparticles that were utilized in the past to achieve extreme wetting properties [6-17].

\section{Materials and Methods}

\subsection{Materials}

Materials used for the production of the $\mathrm{Ca}(\mathrm{OH})_{2}$ nanoparticles were calcium chloride dihydrate ( $\geq 99 \%, \mathrm{CaCl}_{2} \cdot 2 \mathrm{H}_{2} \mathrm{O}$ ), which was obtained from Chem-Lab (Zedelgem Belgium) and an anion exchange resin, Dowex Monosphere-550A-OH (Delfgauw, The Netherlands). Silica $\left(\mathrm{SiO}_{2}\right)$ nanoparticles of $7 \mathrm{~nm}$ in mean diameter were purchased from Sigma-Aldrich (St. Louis, MO, USA). Our group has used these purchased $\mathrm{SiO}_{2}$ nanoparticles in the past to produce superhydrophobic coatings in several investigations, as described in a review book chapter [4]. A water based emulsion composed of amino-modified silanes and fluoro-modified siloxanes was used for the preparation of the dispersions. The ratio of (silanes+siloxanes):water in the emulsion was 1:6 (v/v). Finally, specimens of dolomitic marble, from Thassos, Greece [7], were used in the study.

\subsection{Synthesis and Characterization of $\mathrm{Ca}(\mathrm{OH})_{2}$ Nanoparticles}

$\mathrm{Ca}(\mathrm{OH})_{2}$ nanoparticles were produced according to a recently devised method, which is based on an ion exchange process between an anionic resin and a calcium chloride aqueous solution at room temperature (r.t.) [23]. In particular, an aqueous solution containing $0.1 \mathrm{M}$ of $\mathrm{CaCl}_{2} \bullet 2 \mathrm{H}_{2} \mathrm{O}$ was prepared and mixed with $75 \mathrm{~mL}$ of anion exchange resin, at r.t. and under moderate stirring for $15 \mathrm{~min}$. The resin was then separated from the suspension using a sieve with mesh size of $200 \mu \mathrm{m}$. The separated suspension was mixed with $75 \mathrm{ml}$ of fresh resin at r.t. and under moderate stirring for $30 \mathrm{~min}$. The resin was removed again by sieving and the suspension was subjected to centrifugation for $15 \mathrm{~min}$ at $6000 \mathrm{rpm}$. The precipitated nanoparticles were dried in a vacuum at $50{ }^{\circ} \mathrm{C}$ for $12 \mathrm{~h}$.

The produced $\mathrm{Ca}(\mathrm{OH})_{2}$ nanoparticles were characterized using transmission electron microscopy (TEM; JEOL, 2000FX, Tokyo, Japan) and Fourier-transform infrared spectroscopy (FTIR), which was employed using a Spectrum Spotlight 400 PerkinElmer spectrometer (Waltham, MA, USA).

\subsection{Production and Characterisation of Siloxane+Nanoparticle Coatings}

The produced $\mathrm{Ca}(\mathrm{OH})_{2}$ nanoparticles were dispersed in the silane/siloxane emulsion in various concentrations. The dispersions were stirred mechanically and sprayed onto marble specimens using an airbrush system with a nozzle of $660 \mu \mathrm{m}$ in diameter (Paasche Airbrush, Chicago, IL, USA). Another set of coated marbles were prepared using the silane/siloxane emulsion and $\mathrm{SiO}_{2}$ nanoparticles. Moreover, pure silane/siloxane emulsion (without nanoparticles) was also sprayed onto marble. The morphologies 
of the deposited coatings were investigated using scanning electron microscopy (SEM; JEOL, JSM-6510, Tokyo, Japan).

Static contact angle (CA) and sliding angle (SA) were measured using an optical tensiometer apparatus (Attension Theta, Gothenburg, Sweden). For the measurements of the SAs, the tilt rate was adjusted to $1 \%$ s. The reported angles are averages of five measurements. Variations for the measurements of CAs are provided, and the SAs varied within $\pm 1^{\circ}$.

The measurements of water capillary absorption were performed by the gravimetric sorption technique. Dried weighted coated and uncoated marble blocks were placed on a filter paper pad (Whatman paper, No. 4, Little Chalfont, UK) partially immersed in distilled water. Samples were weighted periodically for a period of $15 \mathrm{~h}$ in total to measure the amount of water absorbed by the specimens. Finally, colorimetric measurements were carried out using a Miniscan XE Plus spectrophotometer (HunterLab, Reston, VA, USA). The reported results are averages of three measurements, and variations are reported.

\section{Results}

The produced nanoparticles were characterized using TEM and FTIR, as shown in Figure 1. According to the TEM image, the sizes of the produced particles were lower than $100 \mathrm{~nm}$, indicating that particles at the nanometer scale were successfully produced. The FTIR spectrum shows characteristic peaks which lead to the identifications of the carbonate $\left(\mathrm{CaCO}_{3}\right)$ and hydroxide $\left(\mathrm{Ca}(\mathrm{OH})_{2}\right)$ compounds of Ca $[24,25]$. In particular, the bands at 1444,877 , and $714 \mathrm{~cm}^{-1}$ correspond to the three different elongation modes of C-O bonds, while the bands at 2983, 2875, and $2513 \mathrm{~cm}^{-1}$ are harmonic vibration of these elongation modes. The thin band at $1795 \mathrm{~cm}^{-1}$ is associated to the carbonate $\mathrm{C}=\mathrm{O}$ bonds The strong band at $3643 \mathrm{~cm}^{-1}$ is related to the $\mathrm{O}-\mathrm{H}$ bonds from hydroxides $[24,25]$.
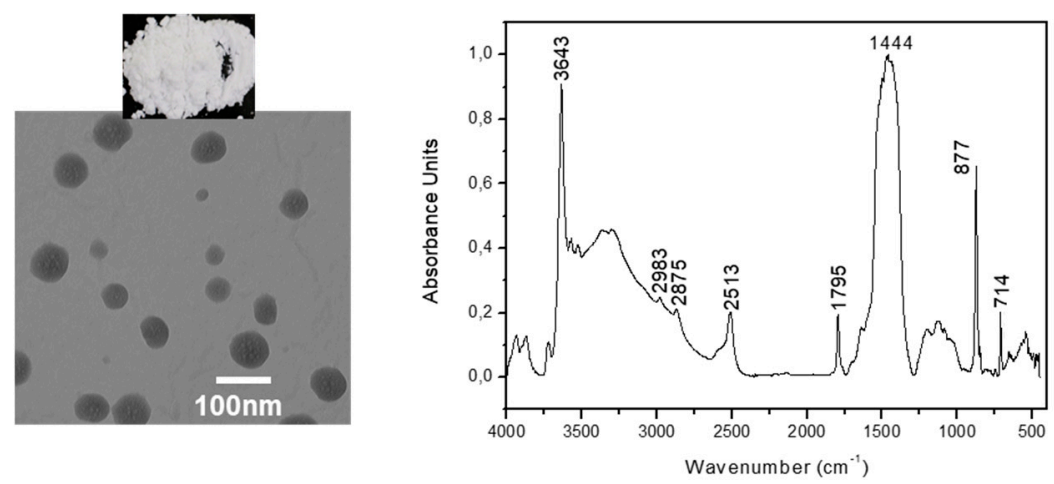

Figure 1. Photograph, TEM image, and FTIR spectrum of the produced nanoparticles.

The surfaces of the siloxane $+\mathrm{Ca}(\mathrm{OH})_{2}$ coatings were characterized using SEM. Indicative images are provided in Figure 2. Adding nanoparticles to the coating's composition results in the formation of surface structures-protrusions that consist of siloxane material mixed with particle agglomerations. As the nanoparticle concentration increases, the surface protrusions become denser, thus promoting surface roughness. The latter is responsible for the extreme wetting properties, which are discussed in the next paragraphs. The scenario revealed in Figure 2 for the siloxane $+\mathrm{Ca}(\mathrm{OH})_{2}$ coatings follows the results reported previously for the effect of $\mathrm{SiO}_{2}$ nanoparticles on the surface structure of siloxane-based composite coatings [6-17]. Surface structures reported for siloxane $+\mathrm{SiO}_{2}$ coatings on marble [6-17] are similar to those shown in Figure 2 for the siloxane $+\mathrm{Ca}(\mathrm{OH})_{2}$ coatings. 

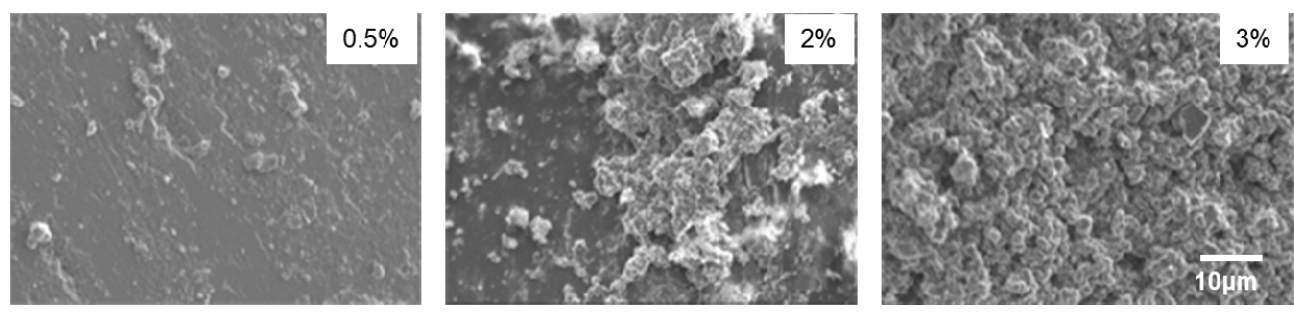

Figure 2. Evolution of the surface structures of the siloxane $+\mathrm{Ca}(\mathrm{OH})_{2}$ coatings. The concentrations $(\mathrm{w} / \mathrm{w})$ of the $\mathrm{Ca}(\mathrm{OH})_{2}$ nanoparticles in the dispersions that were deposited on marble are shown in the upper right corner of each image.

Figure 3 shows the results of the CA and SA measurements of water drops placed on the surfaces of the composite coatings on marble. Two sets of data are included corresponding to the coatings that were prepared using the produced $\mathrm{Ca}(\mathrm{OH})_{2}$ and the purchased $\mathrm{SiO}_{2}$ nanoparticles. According to Figure $3 \mathrm{a}$, the CA of water drops on the surface of pure siloxane (without nanoparticles) is $113^{\circ} \pm 3^{\circ}$, indicating that the application of the water-based emulsion results in the formation of a coating, which shows hydrophobicity [5]. The results in Figure 3a show that CA increases with nanoparticle concentration and eventually becomes very large. Superhydrophobicity $\left(\mathrm{CA}>150^{\circ}\right)$ is evidenced for coatings that were prepared using concentrations of $\mathrm{Ca}(\mathrm{OH})_{2}>1.5 \% \mathrm{w} / \mathrm{w}$ and $\mathrm{SiO}_{2}>1 \% \mathrm{w} / \mathrm{w}$. Overall, siloxane $+\mathrm{SiO}_{2}$ coatings gave larger CAs, compared to the results reported in Figure 3 a for the siloxane $+\mathrm{Ca}(\mathrm{OH})_{2}$ coatings. This difference is within the experimental error for the coatings, which were prepared using the maximum nanoparticle concentration tested herein $(3 \% \mathrm{w} / \mathrm{w})$, i.e., the error bars of $\mathrm{CAs}$ for the two coatings prepared with $\mathrm{SiO}_{2}$ and $\mathrm{Ca}(\mathrm{OH})_{2}$ nanoparticles overlap. The results in Figure $3 \mathrm{a}$ are in agreement with previously published reports that revealed the cross influence effects of particle size and concentration on the wettability of siloxane+nanoparticle composite films. In particular, it was shown that hydrophobicity is enhanced with (i) nanoparticle concentration up to a saturation point [6-9] and (ii) decreasing particle size [26,27]. In the results of Figure 3a, it is seen that $\mathrm{CA}$ increases with nanoparticle concentration reaching a plateau (saturation), which is clearer in the case of the $\mathrm{SiO}_{2}$ nanoparticles. Moreover, larger $\mathrm{CAs}$ are obtained with the siloxane $+\mathrm{SiO}_{2}$ coatings, as the $\mathrm{SiO}_{2}$ nanoparticles are one to two orders of magnitude smaller than the $\mathrm{Ca}(\mathrm{OH})_{2}$ nanoparticles.

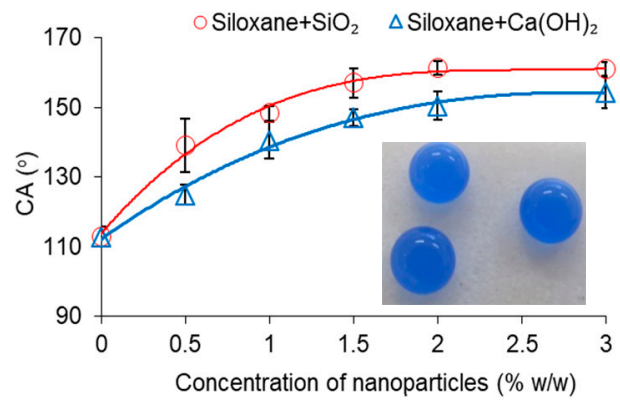

(a)

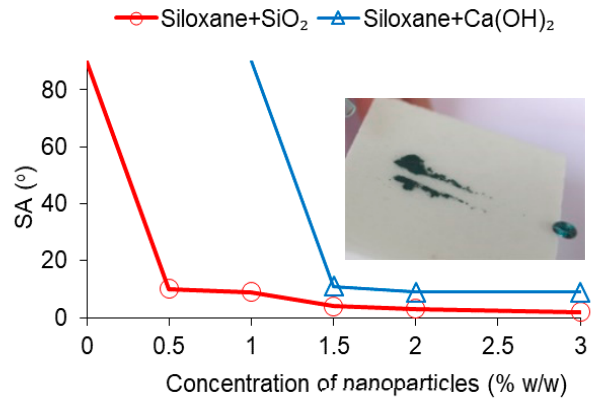

(b)

Figure 3. (a) Static contact angle (CA) and (b) sliding angle (SA) vs the nanoparticle concentration. Data points were (a) fitted with polynomial functions and (b) connected with lines to guide the eye. Coatings prepared using $<0.5 \% \mathrm{w} / \mathrm{w} \mathrm{SiO}_{2}$ and $<1.5 \% \mathrm{w} / \mathrm{w} \mathrm{Ca}(\mathrm{OH})_{2}$ were pinned on the surfaces; therefore, they correspond to a theoretical SA of $90^{\circ}$. Photographs showing (a) resting drops and (b) the self-cleaning process were taken for marble specimens that were coated with superhydrophobic and water repellent composite coatings. The latter were prepared using siloxane and $3 \% \mathrm{w} / \mathrm{w}$ $\mathrm{Ca}(\mathrm{OH})_{2}$ nanoparticles.

Figure $3 \mathrm{~b}$ shows the measurements of $\mathrm{SA}$ of water drops on coated marble specimens. Coatings that were prepared using $<0.5 \% \mathrm{w} / \mathrm{w} \mathrm{SiO}_{2}$ and $<1.5 \% \mathrm{w} / \mathrm{w} \mathrm{Ca}(\mathrm{OH})_{2}$ showed water adhesion, as the water drops were pinned on these surfaces even when they were tilted by $90^{\circ}$. Therefore, it was not possible 
to actually measure SAs on these surfaces which correspond to a theoretical SA $=90^{\circ}$. The SA of water drops on the siloxane $+\mathrm{SiO}_{2}$ surfaces decreased rapidly with nanoparticle concentration and eventually became very small $\left(\mathrm{SA}<10^{\circ}\right)$ and stable when the nanoparticle concentration became $>1 \% \mathrm{w} / \mathrm{w}$. For the coatings that were prepared using the bigger $\mathrm{Ca}(\mathrm{OH})_{2}$ nanoparticles, higher nanoparticle concentration $(>1.5 \% \mathrm{w} / \mathrm{w})$ had to be used to achieve water repellency $\left(\mathrm{SA}<10^{\circ}\right)$.

The superhydrophobic and water repellent performance of the siloxane $+3 \% \mathrm{w} / \mathrm{w} \mathrm{Ca}(\mathrm{OH})_{2}$ composite coating is demonstrated in the photographs of Figure $3 \mathrm{a}, \mathrm{b}$. Resting drops and the self-cleaning process on coated marble specimens are shown in the two photographs. Consequently, the wetting properties of the composite coating mimic those of the lotus leaf surface [2].

The interaction of the siloxane $+3 \% \mathrm{w} / \mathrm{w} \mathrm{Ca}(\mathrm{OH})_{2}$ coating with water was further tested by performing measurements of water capillary absorption. For comparison, uncoated marble blocks and blocks coated by pure siloxane, without nanoparticles, were included in the study. The amount of water absorbed by the specimen per unit area $\left(Q_{i}\right)$ was calculated as follows:

$$
\mathrm{Q}_{\mathrm{i}}=\left(\frac{\mathrm{w}_{\mathrm{i}}-\mathrm{w}_{\mathrm{o}}}{\mathrm{A}}\right) \times 100,
$$

where $w_{i}$ is the weight of the sample after being in contact with water for time $t_{i}, w_{0}$ is the initial weight of the sample prior to the test, and A is the sample's area which was in contact with water during the test. The calculated $Q_{i}$ values were plotted as a function of time $t_{i}$, and the results are presented in Figure 4.

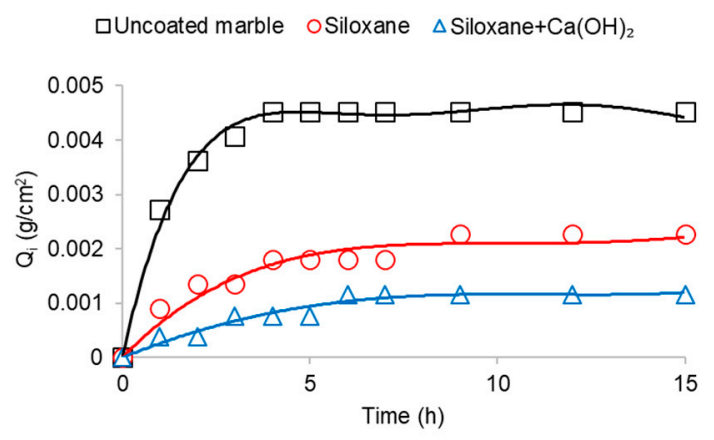

Figure 4. Amounts of absorbed water per unit area $\left(Q_{i}\right)$ as a function of treatment time $t_{i}$, for three samples: (i) uncoated marble; (ii) marble coated by pure siloxane; and (iii) marble coated by a composite coating, which was prepared using siloxane and $3 \% \mathrm{w} / \mathrm{w} \mathrm{Ca}(\mathrm{OH})_{2}$ nanoparticles (siloxane $\left.+\mathrm{Ca}(\mathrm{OH})_{2}\right)$. Data points were fitted with polynomial functions to guide the eye.

The results of Figure 4 show that the specimens became saturated in absorbed water. This is evidenced by the recorded plateaus of the three $Q_{i}-t_{i}$ curves. The amounts of absorbed water follow the order: uncoated sample -> sample coated by siloxane $->$ sample coated by siloxane $+\mathrm{Ca}(\mathrm{OH})_{2}$, with the latter being the sample that absorbed the least amount of water at each specific $t_{i}$. Specifically, by taking into consideration the last three $\left(t_{i}=9,12\right.$, and $\left.15 h\right)$ measurements of $Q_{i}$ for each curve, which clearly correspond to the plateaus of the curves, average-maximum values of $Q_{i}$ were calculated as follows: $0.0045 \mathrm{~g} / \mathrm{cm}^{2}$ for the uncoated sample, $0.0023 \mathrm{~g} / \mathrm{cm}^{2}$ for the sample coated by siloxane, and $0.0012 \mathrm{~g} / \mathrm{cm}^{2}$ for the sample coated by siloxane $+\mathrm{Ca}(\mathrm{OH})_{2}$. The hydrophobic siloxane coating offers protection against the capillary absorption of water. The protection, however, is enhanced when the superhydrophobic and water repellent siloxane $+\mathrm{Ca}(\mathrm{OH})_{2}$ coating is applied on the marble surface.

For the maxima amounts of absorbed water, corresponding to the plateaus of the curves in Figure 4 , the relative reduction of water absorption by capillarity $(\mathrm{RC} \%)$ was calculated using the following Equation:

$$
\mathrm{RC} \%=\left(\frac{\mathrm{Q}_{\mathrm{u}}-\mathrm{Q}_{\mathrm{c}}}{\mathrm{Q}_{\mathrm{u}}}\right) \times 100,
$$


where $Q_{u}$ and $Q_{c}$ are the maxima $Q_{i}$ measured for the uncoated and coated marble specimens, respectively. An ideal coating should correspond to $\mathrm{RC} \%=100$, as it should eliminate the penetration of liquid water into the pore network of the stone. Using Equation (2), it is calculated that the application of the siloxane coating on marble results in a reduction of the amount of absorbed water by $49 \%$. The RC $\%$ increased to 73 when the superhydrophobic and water repellent siloxane $+\mathrm{Ca}(\mathrm{OH})_{2}$ coating was applied on marble.

Finally, the optical effects of the siloxane and siloxane $+\mathrm{Ca}(\mathrm{OH})_{2}$ coatings on marble were evaluated through colorimetric measurements. The global color differences $\left(\Delta \mathrm{E}^{*}\right)$ of marble, induced upon coating application, was derived from:

$$
\Delta \mathrm{E}^{*}=\sqrt{\left(\mathrm{L}_{\mathrm{c}}^{*}-\mathrm{L}_{\mathrm{u}}^{*}\right)^{2}+\left(\mathrm{a}_{\mathrm{c}}^{*}-\mathrm{a}_{\mathrm{u}}^{*}\right)^{2}+\left(\mathrm{b}_{\mathrm{c}}^{*}-\mathrm{b}_{\mathrm{u}}^{*}\right)^{2}}
$$

where $L^{*}, a^{*}$, and $b^{*}$ are the components of the CIE 1976 scale, respectively. The " $c$ " and " $u$ " subscript characters indicate the coated and uncoated specimens, respectively. The results of the $L^{*}, a^{*}$, and $b^{*}$ measurements are summarized in Table 1. Using Equation (3) and the values of Table 1, it is calculated that $\Delta \mathrm{E}^{*}=0.36 \pm 0.04$ for the marble specimen that was coated with siloxane and $\Delta \mathrm{E}^{*}=3.76 \pm$ 0.03 for the marble specimen that was coated with siloxane $+\mathrm{Ca}(\mathrm{OH})_{2}$. According to the literature, color variations which correspond to $\Delta \mathrm{E}^{*}<3$ are insignificant as they are not perceived by human eye [28-30]; the accepted level for conservation purposes is $\Delta \mathrm{E}^{*}<5$ [28]. Consequently, the results, which are reported in Table 1 , suggest that the siloxane material $\left(\Delta \mathrm{E}^{*}=0.36\right)$ has a negligible effect on the color of the marble. However, when $\mathrm{Ca}(\mathrm{OH})_{2}$ nanoparticles are added in the coating, then the treatment of the marble is accompanied by a noticeable visual effect $\left(\Delta \mathrm{E}^{*}=3.76\right)$ which, however, is not very far away from the human perception threshold value and clearly below the accepted level for conservation purposes.

Table 1. Color coordinates measured for uncoated marble and marble specimens coated with siloxane and siloxane $+\mathrm{Ca}(\mathrm{OH})_{2}$. The composite coating was prepared using $3 \% \mathrm{w} / \mathrm{w} \mathrm{Ca}(\mathrm{OH})_{2}$ nanoparticles.

\begin{tabular}{cccc}
\hline & Uncoated & Siloxane & Siloxane+Ca(OH) \\
\hline$L^{*}$ & $91.67 \pm 0.03$ & $91.34 \pm 0.05$ & $95.41 \pm 0.01$ \\
$a^{*}$ & $-0.24 \pm 0.01$ & $-0.29 \pm 0.01$ & $-0.06 \pm 0.01$ \\
$b^{*}$ & $3.45 \pm 0.01$ & $3.57 \pm 0.02$ & $3.16 \pm 0.02$ \\
\hline
\end{tabular}

\section{Conclusions}

The major finding from this work is that superhydrophobic and water repellent coatings can be produced using dispersions of $\mathrm{Ca}(\mathrm{OH})_{2}$ nanoparticles in water-based silane/siloxane emulsions. $\mathrm{Ca}(\mathrm{OH})_{2}$ is chemically compatible with limestone and limestone-like rocks (marble, travertine), which are undoubtfully the most common stones found in buildings and objects of the cultural heritage. Siloxane-based materials are commonly used for consolidation purposes. Therefore, the siloxane $+\mathrm{Ca}(\mathrm{OH})_{2}$ composite coatings, which are formed by spraying the aforementioned dispersions onto the stone substrate, have the potential to be used for conservation purposes.

The $\mathrm{Ca}(\mathrm{OH})_{2}$ nanoparticles (Figure 1 ) were synthesized following an easy, ion exchange process, and the extreme wetting properties, which were achieved on the surface of the composite coatings (Figure 2), were evidenced by the high CA $>150^{\circ}$ and the low $\mathrm{SA}<10^{\circ}$ (Figure 3) of water drops. Composite coatings offered good protection against water penetration by capillarity (Figure 4 ) and had a small effect on the color of marble (Table 1).

Further and more detailed studies should be carried out in the future to investigate the durability of the siloxane $+\mathrm{Ca}(\mathrm{OH})_{2}$ coatings and their effects on the breathability of marble. 
Author Contributions: Conceptualization, I.K.; investigation, A.C.; data curation, A.C. and I.K.; writing-original draft preparation, I.K.; writing-review and editing, I.K. and I.P.; project administration, I.P.; All authors have read and agreed to the published version of the manuscript.

Funding: This research received no external funding.

Acknowledgments: The authors would like to thank Shrief Eissa for his assistance with the TEM studies, Dimitrios Lampakis for his contribution to the FTIR measurements and Dimitra Aslanidou for her assistance in the production of the nanoparticles.

Conflicts of Interest: The authors declare no conflict of interest.

\section{References}

1. Artesani, A.; Di Turo, F.; Zucchelli, M.; Traviglia, A. Recent advances in protective coatings for cultural heritage-An overview. Coatings 2020, 10, 217. [CrossRef]

2. Barthlott, W.; Neinhuis, C. Purity of the sacred lotus, or escape from contamination in biological surfaces. Planta 1997, 202, 1-8. [CrossRef]

3. Feng, L.; Zhang, Y.; Xi, J.; Zhu, Y.; Wang, N.; Xia, F.; Jiang, L. Petal effect: A superhydrophobic state with high adhesive force. Langmuir 2008, 24, 4114-4119. [CrossRef]

4. Karapanagiotis, I.; Manoudis, P. Superhydrophobic and water repellent polymer-nanoparticle composite films. In Industrial Applications for Intelligent Polymers and Coatings; Hosseini, M., Makhlouf, A.S.H., Eds.; Springer: Cham, Switzerland, 2016; pp. 205-221.

5. Karapanagiotis, I.; Hosseini, M. Superhydrophobic coatings for the protection of natural stone. In Advanced Materials for the Conservation of Stone; Hosseini, M., Karapanagiotis, I., Eds.; Springer: Cham, Switzerland, 2018; pp. 1-25.

6. Manoudis, P.; Papadopoulou, S.; Karapanagiotis, I.; Tsakalof, A.; Zuburtikudis, I.; Panayiotou, C. Polymer-silica nanoparticles composite films as protective coatings for stone-based monuments. J. Phys. Conf. Ser. 2007, 61, 1361-1365. [CrossRef]

7. Manoudis, P.; Tsakalof, A.; Karapanagiotis, I.; Zuburtikudis, I.; Panayiotou, C. Fabrication of super-hydrophobic surfaces for enhanced stone protection. Surf. Coat. Technol. 2009, 203, 1322-1328. [CrossRef]

8. Manoudis, P.N.; Karapanagiotis, I.; Tsakalof, A.; Zuburtikudis, I.; Kolinkeová, B.; Panayiotou, C. Superhydrophobic films for the protection of outdoor cultural heritage assets. Appl. Phys. A-Mater. 2009, 97, 351-360. [CrossRef]

9. Chatzigrigoriou, A.; Manoudis, P.N.; Karapanagiotis, I. Fabrication of water repellent coatings using waterborne resins for the protection of the cultural heritage. Macromol. Symp. 2013, 331-332, 158-165. [CrossRef]

10. Facio, D.S.; Mosquera, M.J. Simple strategy for producing superhydrophobic nanocomposite coatings in situ on a building substrate. ACS Appl. Mater. Interfaces 2013, 5, 7517-7526. [CrossRef]

11. Aslanidou, D.; Karapanagiotis, I.; Panayiotou, C. Tuning the wetting properties of siloxane-nanoparticle coatings to induce superhydrophobicity and superoleophobicity for stone protection. Mater. Des. 2016, 108, 736-744. [CrossRef]

12. Helmi, F.M.; Hefni, Y.K. Using nanocomposites in the consolidation and protection of sandstone. Int. J. Conserv. Sci. 2016, 7, 29-40.

13. Pino, F.; Fermo, P.; La Russa, M.; Ruffolo, S.; Comite, V.; Baghdachi, J.; Pecchioni, E.; Fratini, F.; Cappelletti, G. Advanced mortar coatings for cultural heritage protection. Durability towards prolonged UV and outdoor exposure. Environ. Sci. Pollut. Res. 2017, 24, 12608-12617. [CrossRef] [PubMed]

14. Facio, D.S.; Carrascosa, L.A.M.; Mosquera, M.J. Producing lasting amphiphobic building surfaces with self-cleaning properties. Nanotechnology 2017, 28, 265601. [CrossRef]

15. Aslanidou, D.; Karapanagiotis, I.; Lampakis, D. Waterborne superhydrophobic and superoleophobic coatings for the protection of marble and sandstone. Materials 2018, 11, 585. [CrossRef] [PubMed]

16. Mosquera, M.J.; Carrascosa, L.A.M.; Badreldin, N. Producing superhydrophobic/oleophobic coatings on Cultural Heritage building materials. Pure Appl. Chem. 2018, 90, 551-561. [CrossRef]

17. Karapanagiotis, I.; Ntelia, E. Superhydrophobic Paraloid B72. Prog. Org. Coat. 2020, 139, 105224. 
18. Tian, S.; Liu, S.; Gao, F.; Ren, J. Preparation and assessment of superhydrophobic organic-inorganic hybrid coatings for conservation of Yungang Grottoes. Mater. Res. Soc. Symp. Proc. 2011, 1319, 333-338. [CrossRef]

19. MacMullen, J.; Radulovic, J.; Zhang, Z.; Dhakal, H.N.; Daniels, L.; Elford, J.; Leost, M.A.; Bennett, N. Masonry remediation and protection by aqueous silane/siloxane macroemulsions incorporating colloidal titanium dioxide and zinc oxide nanoparticulates: Mechanisms, performance and benefits. Constr. Build. Mater. 2013, 49, 93-100. [CrossRef]

20. Cappelletti, G.; Fermo, P.; Camiloni, M. Smart hybrid coatings for natural stones conservation. Prog. Org. Coat. 2015, 78, 511-516. [CrossRef]

21. La Russa, M.F.; Rovella, N.; De Buergo, M.A.; Belfiore, C.M.; Pezzino, A.; Crisci, G.M.; Ruffolo, S.A. Nano-TiO 2 coatings for cultural heritage protection: The role of the binder on hydrophobic and self-cleaning efficacy. Prog. Org. Coat. 2016, 91, 1-8. [CrossRef]

22. Zarzuela, R.; Carbú, M.; Gil, M.L.A.; Cantoral, J.M.; Mosquera, M.J. Ormosils loaded with $\mathrm{SiO}_{2}$ nanoparticles functionalized with Ag as multifunctional superhydrophobic/biocidal/consolidant treatments for buildings conservation. Nanotechnology 2019, 30, 345701. [CrossRef]

23. Taglieri, G.; Daniele, V.; Del Re, G.; Volpe, R. A new and original method to produce $\mathrm{Ca}(\mathrm{OH})_{2}$ nanoparticles by using an anion exchange resin. Adv. Nanoparticles 2015, 4, 17-24. [CrossRef]

24. Galván-Ruiz, M.; Hernández, J.; Baños, L.; Noriega-Montes, J.; Rodríguez-García, M.E. Characterization of calcium carbonate, calcium oxide, and calcium hydroxide as starting point to the improvement of lime for their use in construction. J. Mater. Civil Eng. 2009, 21, 625-708. [CrossRef]

25. Gunasekaran, S.; Anbalagan, G.; Pandi, S. Raman and Infrared spectra of carbonates of calcite structure. J. Raman Spectrosc. 2006, 37, 892-899. [CrossRef]

26. Manoudis, P.N.; Karapanagiotis, I. Modification of the wettability of polymer surfaces using nanoparticles. Prog. Org. Coat. 2014, 77, 331-338. [CrossRef]

27. Karapanagiotis, I.; Manoudis, P.N.; Savva, A.; Panayiotou, C. Superhydrophobic polymer-particle composite films produced using various particle sizes. Surf. Interface Anal. 2012, 44, 870-875. [CrossRef]

28. Pedna, A.; Pinho, L.; Frediani, P.; Mosquera, M.J. Obtaining $\mathrm{SiO}_{2}$-fluorinated PLA bionanocomposites with applicationas reversible and highly-hydrophobic coatings of buildings. Prog. Org. Coat. 2016, 90, 91-100. [CrossRef]

29. Gherardi, F.; Roveri, M.; Goidanich, S.; Toniolo, L. Photocatalytic nanocomposites for the protection of European architectural heritage. Materials 2018, 11, 65. [CrossRef]

30. Pargoletti, E.; Motta, L.; Comite, V.; Fermo, P.; Cappelletti, G. The hydrophobicity modulation of glass and marble materials by different Si-based coatings. Prog. Org. Coat. 2019, 136, 105260. [CrossRef] 